\title{
Thermophysical and Mechanical Characterization of Poto-Poto Compressed Blocks for Use as Fill Material
}

\author{
Kowa K. Eric ${ }^{1}$, Jean Claude Damfeu², Pettang J. Ursulala², Joel Ducourneau³, Paul Woafo', \\ Chispin Pettang 2 \\ ${ }^{1}$ Physics Department, University of Yaounde I, Yaounde, Cameroon \\ ${ }^{2}$ Laboratory of Energy, Water and Environment, National Advanced School of Engineering, University of Yaounde I, Yaounde, \\ Cameroon \\ ${ }^{3}$ CNRS, LEMTA, UMR 7563, Vandœuvre-lès-Nancy, F-54500, France \\ Email: damfeuclaude@yahoo.fr
}

How to cite this paper: Eric, K.K., Damfeu, J.C., Ursulala, P.J., Ducourneau, J., Woafo, P. and Pettang, C. (2021) Thermophysical and Mechanical Characterization of PotoPoto Compressed Blocks for Use as Fill Material. Materials Sciences and Applications, 12, 437-459.

https://doi.org/10.4236/msa.2021.1210029

Received: August 26, 2021

Accepted: October 26, 2021

Published: October 29, 2021

Copyright $\odot 2021$ by author(s) and Scientific Research Publishing Inc. This work is licensed under the Creative Commons Attribution International License (CC BY 4.0).

http://creativecommons.org/licenses/by/4.0/

(c) (i) Open Access

\begin{abstract}
This article is devoted to the thermophysical and mechanical study of an eco-material, poto-poto. The objective is to study the influence of the addition of bamboo fibers on the thermophysical properties of the material, while verifying that it complies with the mechanical standards in Cameroon. A double study is therefore carried out: a mechanical characterization whose objective is to determine the mechanical properties (compressive strength, flexural strength and Young's modulus) and a thermophysical characterization whose objective is to determine the thermal conductivity. For the thermophysical characterization, the asymmetric hot plane experimental setup based on 1D quadrupole modelling was developed and simulated for the estimation of thermal effusivity $\mathrm{E}$ and volume heat capacity $\rho C_{p}$. The obtained experimental results show that the apparent thermal conductivity of the developed materials decreases with increasing fibers. Although the reference material ( $0 \%$ fibers) has a much higher conductivity than the ordinary sand block $\left(1.15 \mathrm{Wm}^{-1} \mathrm{~K}^{-1}\right)$, the addition of fibers, already at $2 \%$, contributes to decrease this conductivity $\left(0.95 \mathrm{Wm}^{-1} \mathrm{~K}^{-1}\right)$. From the point of view of thermal insulation and energy savings, the thermal conductivity results obtained show that the use of these materials with a maximum fibercontent of $6 \%$ would be a better thermal insulator than sand block or compressed earth brick. The compressive strength obtained is such that $R_{c}>0.6 \mathrm{MPa}$. All the materials developed meet the design standards when used as infill.
\end{abstract}

\section{Keywords}

Thermoméchanical Charactézisation, Poto-Poto, Thermal Insulation, 


\section{Introduction}

In Cameroon, demographic growth is constant, particularly in urban areas. At the same time, there is a serious lack of infrastructure (availability of housing, extension of urban technical networks, availability of plots of land, etc.). Among the immediate negative effects of this situation, which seems to surprise every time, we can mention: the energy crisis, health problems, price inflation. Some studies carried out by the Ministry of Public Works [1] in Cameroon indicate, for example, that the energy spent on domestic use and the construction of buildings in conventional materials is increasing. This growth affects thermal comfort both outside and inside the building envelope.

One solution to these multiple problems could be sustainable construction, as is the case elsewhere, through strategies that take into account three parameters: thermal comfort, environmental impact and health impact. In order to integrate these three criteria and other properties such as thermal and acoustic insulation, some countries have set up genuine environmental construction policies. Examples include: the HQE (Haute Qualité Environnementale) approach in France [2], BREEAM (BRE Environmental Assessment Method) in the UK [2], LEED (Leadership in Energy and Environmental Design) in the USA [2].

Although several authors in Cameroon have already addressed the issue of local materials, we continue to lag far behind in taking into account the environmental and energy impact in construction policy. Most of Cameroon's large cities (Douala, Yaoundé) use $90 \%$ of non-biodegradable construction materials, in this case breeze blocks, made in large part from cement, which has major drawbacks, notably the fact that it requires a high cooking temperature $\left(1450^{\circ} \mathrm{C}\right)$, achieved mainly by using fossil fuels. This process uses about $1700 \mathrm{MJ} /$ tone of clinker [3]. The gas emission balance of the cement manufacturing process is estimated at 0.8 tons of $\mathrm{CO}_{2}$ equivalent per ton of clinker. Therefore, the cement industry is an emitter of greenhouse gases.

Nevertheless, there has been a gradual decrease in energy consumption in the building sector over the last decade. This is mainly due to the consideration of the environment in the life cycle (eco-design) of construction products. Worldwide, and particularly in Africa [4] [5], there is a renewed interest in the use of natural materials such as wood, straw, plant fibers, earth and hemp.

In Cameroon, in regions such as the East, South, West and part of the Centre, most constructions are made of poto-poto (local material), one of the main raw materials being earth. Other materials encountered are: pozzolan concrete (Foumbam-Cameroon), wood concrete (Bafoussam-Cameroon) or in Northern Cameroon straw concrete materials [6]. Most of these materials contribute to limiting greenhouse gas emissions thanks to their capacity to trap $\mathrm{CO}_{2}$ and ensure natu- 
ral regulation. Moreover, the use of these local materials, which are biodegradable and available for the most part, also makes it possible to reduce construction costs and energy costs, as the energy expenses linked to consumption are greatly reduced.

The requirements of sustainable development now recommend that, before a building is erected, the properties of the materials that make up its envelope should be known, and the mechanical, thermal, acoustic and sound characteristics should be controlled. Moreover, due to the variable ambient thermal and hydrometric conditions, these materials are the seat of several phenomena: humidification, phase change and capillarity.

Several authors have been interested in the study of local materials made from earth.

Mekhermeche [7] and Bessenouci [8] have carried out thermomechanical characterisation of composite materials based on earth with the addition of sand or palm fibre. They conclude that all these materials have compressive and flexural strengths that meet the civil engineering standards for building envelope fillers. Those with an addition of at least 3\% palm fibre can improve the thermal insulation of a building. But in their studies they give no information on how the thermal properties were determined. Nguyen [9] studied the influence of the addition of a binder on the mechanical properties of concrete made from hemp fibres. He obtained compressive strengths varying between $0.1 \mathrm{MPa}$ and 2.9 $\mathrm{MPa}$ depending on the binder content in the different materials. However, in his work he does not investigate the thermal insulation performance of these materials. The mechanical properties of the concretes: autoclaved cellular, hemp and vertically perforated clay bricks were studied by Samri [10]. He obtained compressive strengths around $3 \mathrm{MPa}$ for vertically perforated clay bricks. In contrast, hemp concretes have low mechanical properties ranging from $0.35 \mathrm{MPa}$ to $0.80 \mathrm{MPa}$, which is in agreement with the work of Mekhermeche [7]. Also, in his work no study of the energy aspect of the materials was carried out. [11] [12], studied the possibilities of improving the physical and mechanical properties of laterite bricks with the incorporation of pozzolan, industrial lime and thermally activated clay. He came to the conclusion that increasing the percentage of lime in mud bricks increases the compressive strength and slightly decreases the bulk density and the water absorption rate. Also in his work, he does not study the influence of thermal inertia and thermal insulation. Meukam et al. [13] studied the thermal properties of mud bricks with the addition of a percentage of natural Djoungo pozzolan (particle diameter $12.5 \mathrm{~mm}$ ). He concluded that the addition of a percentage of pozzolan decreases the thermal conductivity of the composite material. However, these studies do not indicate how the thermal conductivity of the brick might vary if the diameter of the pozzolan aggregates is increased or decreased. Pepple et al. [14] also studied cement-stabilized earth bricks in which he added sea shells, but the influence of the addition of sea shells on the thermophysical properties was not investigated in his work. 
The objectives of the work carried out in this study are:

- To know the influence on the mechanical properties of adding Chinese bamboo fibers to a non-lateritic soil block.

- Check whether the use of this soil with the simple addition of cement-free fibers can be used as a filling material for the building envelope.

- Propose a simple model for its thermophysical properties in order to check whether it also satisfies the properties of a thermal insulating material.

Knowledge of these properties (mechanical and thermophysical) would thus contribute to a double aspect: economic (valorization of local materials) and environmental (regulation of energy consumption).

\section{Materials Used and Procedure for Making Our Samples}

\subsection{Sample Preparation}

\subsubsection{The Land}

The earth material (Figure 1) studied in this article is a material from a clay mass taken from the city of Yaoundé (Cameroon) on the Etetak site near the Sacred Heart Catholic Primary School of Mokolo in the Yaoundé 2 district. This site, rich in laterites, has supplied many backfill sites, particularly roads, as traces of excavations by excavators are left on the vertical faces. The various reworked samples representative of the sites were taken according to the recommendations of standard NF EN 932-1 (1996). The quantities used for the laboratory tests or test samples were taken by quartering, from the large representative samples of the materials according to standard NF EN 932-2 (1999).

First, we carried out a particle size analysis and a consistency study of this soil according to the Cameroonian Standard for BTC (NC 102-114, 2002-2006) [15] [16]. The purpose of this particle size analysis is to determine the physical and geotechnical properties with a view to using our material in the filling of a building envelope. Its texture curve, shown in Figure 2, shows that it is slightly out of its grading range.

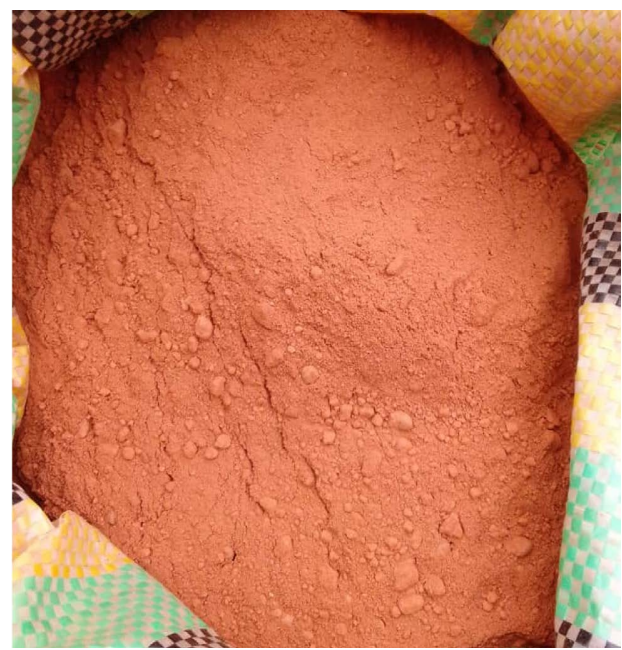

Figure 1. Soil removed. 


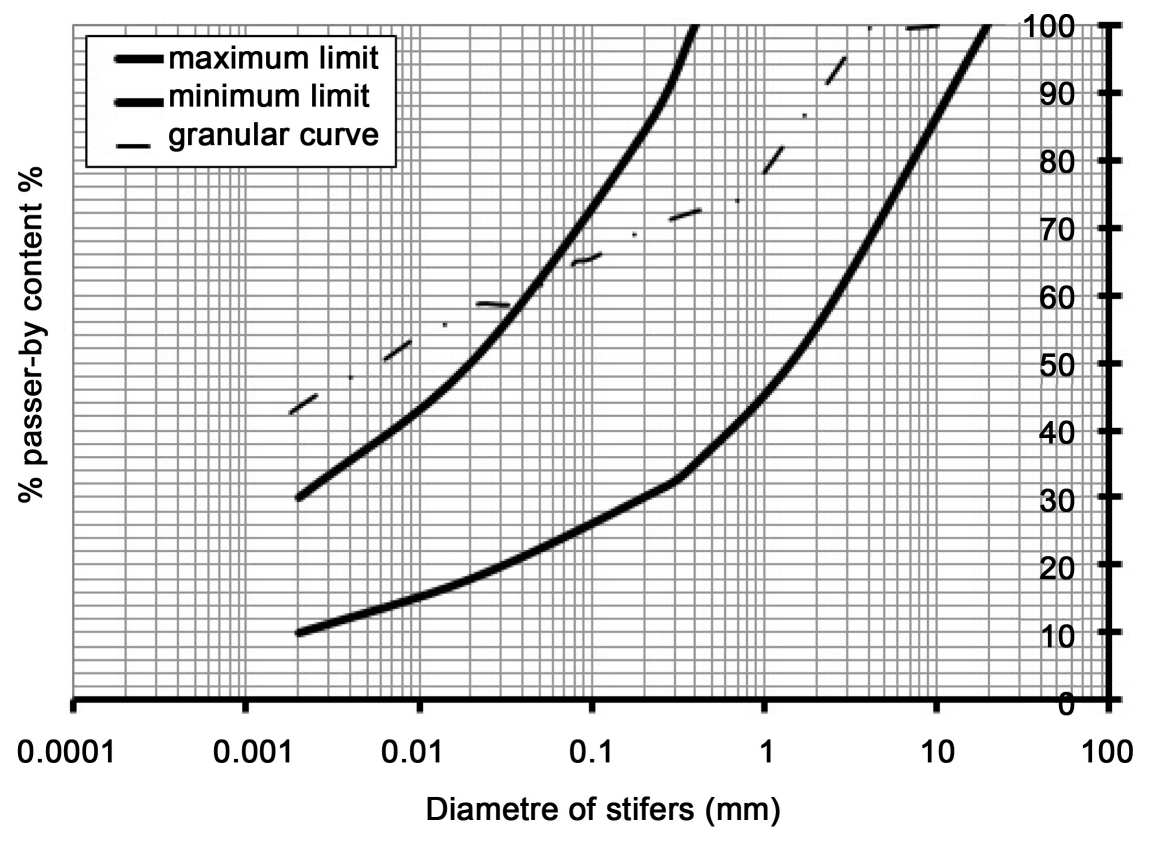

Figure 2. Texture diagram of our soil material.

The results of the particle size synthesis of this soil are presented in Table 1.

According to the results in Table 1, this soil has a clay content of $40.45 \%$, which is well above the recommended limit of $30 \%$ for compressed earth bricks in the Cameroonian standard NC 102-114 [16]. This can be justified, as its texture curve (Figure 1) is not totally within the grading range. This already shows that the use of this soil requires the addition of additives in order to further solidify it. Its plasticity index of $16 \%$ is in accordance with the standard for the use of a filling material in civil engineering $(2 \%<\mathrm{Ip}<30 \%)$, let us note nevertheless that its value relatively far from $30 \%$, is already an indicator that this earth is not very flexible, it will thus tend to break quickly if it is subjected to strong constraints in flexion. The use of this soil in its raw state can be recommended in dry tropical areas.

\subsubsection{Chinese Bamboo Fibers}

After sampling, the bamboo was dried at a temperature of $105^{\circ} \mathrm{C}$, then with the help of a knife we defibrated it to the respective dimensions according to each test to be carried out. These were $2 \mathrm{~mm}$ thick and $15 \mathrm{~cm}$ long for the bending and modulus of elasticity tests (Figure $3(\mathrm{~b})$ ); and $2 \mathrm{~cm}$ thick and $3 \mathrm{~cm}$ long for the compression tests (Figure 3(a) and Figure 3(c)). They were pre-wetted before being mixed in the dry soil. The aim was to neutralize the high absorbency of the fibers in order to avoid cracking of the specimens.

\subsection{Procedure for Making up the Specimens}

For the design of the specimens (Figure 4), we considered the characteristics of the soil as presented in Table 2. We then carried out a preliminary mixing of the fine soil and water for a good intrusion of the paste. The bamboo strips 
Table 1. Particle size analysis and consistency of soil material.

\begin{tabular}{cccccc}
\hline \multicolumn{5}{c}{ Particle size synthesis } \\
\hline Colour & Aspect & $\begin{array}{c}\text { of gravel } \\
\Phi \geq 2 \mathrm{~mm}\end{array}$ & $\begin{array}{c}\text { of sand } \\
2 \geq \Phi \geq 0.2 \mathrm{~mm}\end{array}$ & $\begin{array}{c}\text { of silt } \\
0.02 \geq \Phi \geq 0.002 \mathrm{~mm}\end{array}$ & $\begin{array}{c}\text { of clay } \\
\Phi \leq 0.02 \mathrm{~mm}\end{array}$ \\
\hline Red & Sandy & 10.75 & 30.53 & 18.27 & 40.45 \\
\hline & \multicolumn{5}{c}{ Consistency limit (\%) } \\
\hline Liquidity limit & 61.8 & & \\
Plasticity limit & 45.8 & & \\
Plasticity index & 16.0 & & \\
\hline
\end{tabular}

Table 2. Parameters of the different aggregates used for the casting of the mechanical characterization samples.

\begin{tabular}{ccccccccccc}
\hline & \multicolumn{2}{c}{ Thermophysics } & \multicolumn{2}{c}{ Compression } & \multicolumn{3}{c}{ Flexion } \\
\cline { 2 - 10 } & \multicolumn{2}{c}{$10 \mathrm{~cm} \times 10 \mathrm{~cm} \times 4 \mathrm{~cm}$} & \multicolumn{2}{c}{$4 \mathrm{~cm} \times 4 \mathrm{~cm} \times 4 \mathrm{~cm}$} & \multicolumn{2}{c}{$4 \mathrm{~cm} \times 4 \mathrm{~cm} \times 16 \mathrm{~cm}$} \\
\hline$\%$ fiber & $\mathrm{mb}(\mathrm{g})$ & $\mathrm{mT}(\mathrm{g})$ & $\mathrm{me}(\mathrm{g})$ & $\mathrm{mb}(\mathrm{g})$ & $\mathrm{mT}(\mathrm{g})$ & $\mathrm{me}(\mathrm{g})$ & $\mathrm{mb}(\mathrm{g})$ & $\mathrm{mT}(\mathrm{g})$ & $\mathrm{me}(\mathrm{g})$ \\
\hline $0 \%$ & 0 & 600 & 135 & 0 & 150 & 33.75 & 0 & 500 & 112.5 \\
$2 \%$ & 12 & 588 & 132.3 & 3 & 147 & 33.075 & 10 & 490 & 110.25 \\
$4 \%$ & 24 & 576 & 129.6 & 6 & 144 & 32.4 & 20 & 480 & 108 \\
$6 \%$ & 36 & 564 & 126.9 & 9 & 141 & 31.725 & 30 & 470 & 105.75 \\
\hline
\end{tabular}

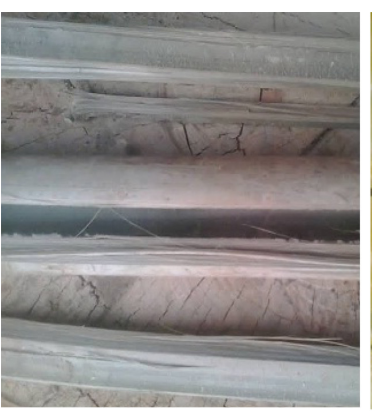

(a)

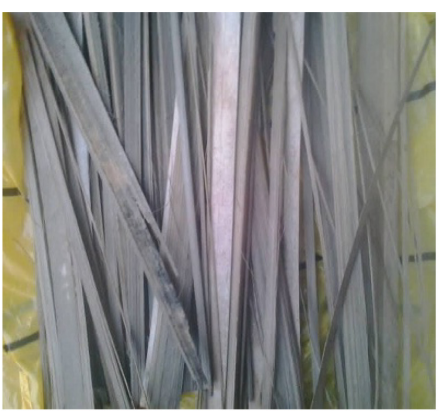

(b)

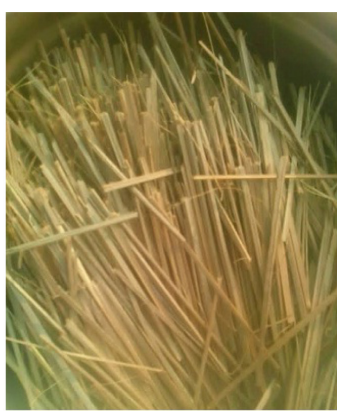

(c)

Figure 3. Bamboo fibres.

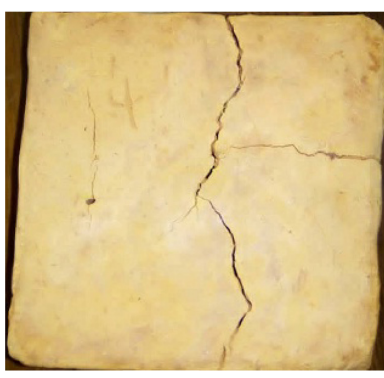

(a)

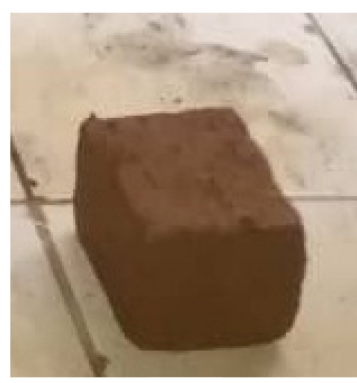

(b)

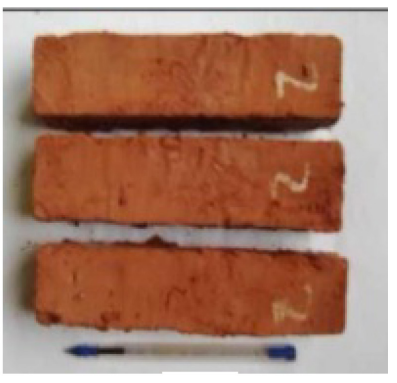

(c)

Figure 4. Test tube (a) for thermo; (b) for compression; (c) for bending. 
(respectively with the required dimensions according to the test to be carried out) were then pre-wetted before being introduced into the dry mixture. Three types of metal moulds of parallelepiped shape (width, height, length) were then used: $4 \mathrm{~cm} \times 4 \mathrm{~cm} \times 16 \mathrm{~cm}$ (French standard Cratère NFP 31-21222, 23 [3]) for the bending tests, another one of square shape $4 \mathrm{~cm} \times 4 \mathrm{~cm} \times 4 \mathrm{~cm}$ (Standard NFP 98-33522, 23 [3]) for the compression tests and $10 \mathrm{~cm} \times 10 \mathrm{~cm} \times 4 \mathrm{~cm}$ for the thermophysical tests.

Once the bricks have been made as shown in Figure 4, they are cured for 7 days. Finally, the specimens are stored before demoulding at a temperature of $<25^{\circ} \mathrm{C}$.

The compositions of the samples are then as follows.

\section{Experimental Device}

\subsection{Experimental Device for Thermophysical Characterisation}

The experimental set-up is as shown in Figure 5.

The device shown in Figure 6 consists of using a flat heating element $(10 \mathrm{~cm} \times$ $10 \mathrm{~cm}$ ) fitted with a "MINCO $230 \Omega \mathrm{P}$ " heating resistor (probe see Figure 4) inserted between two flat surface samples of the material to be characterized. The heating probe and the sample preferably have the same surface, the aim being to be able to make the hypothesis that the heat transfer is unidirectional during the time when the lateral convective losses are negligible. Temperature acquisition is done using a type $\mathrm{K}$ thermocouple with $0.002 \mathrm{~mm}$ diameter wires, glued to the centre of the MINCO HK 5178 heating element.

First, we calibrated the heating element. The heating element has a thickness $e_{h}=0.25 \mathrm{~mm}$ and a volumetric heat capacity $\rho_{h} c_{h}=1.2 \times 10^{6} \mathrm{Jm}^{-3} \mathrm{~K}^{-1}$. The thermal conductivity of the polystyrene measured by the mini hot plane method [17] is $0.032 \mathrm{Wm}^{-1} \mathrm{~K}^{-1}$ and its heat capacity by volume $\rho_{i} c_{p i}=48,000 \mathrm{Jm}^{-3} \mathrm{~K}^{-1}$. The thickness of the sample is chosen so that the semi-infinite medium assumption for the sample is verified for at least a few seconds. The whole experimental

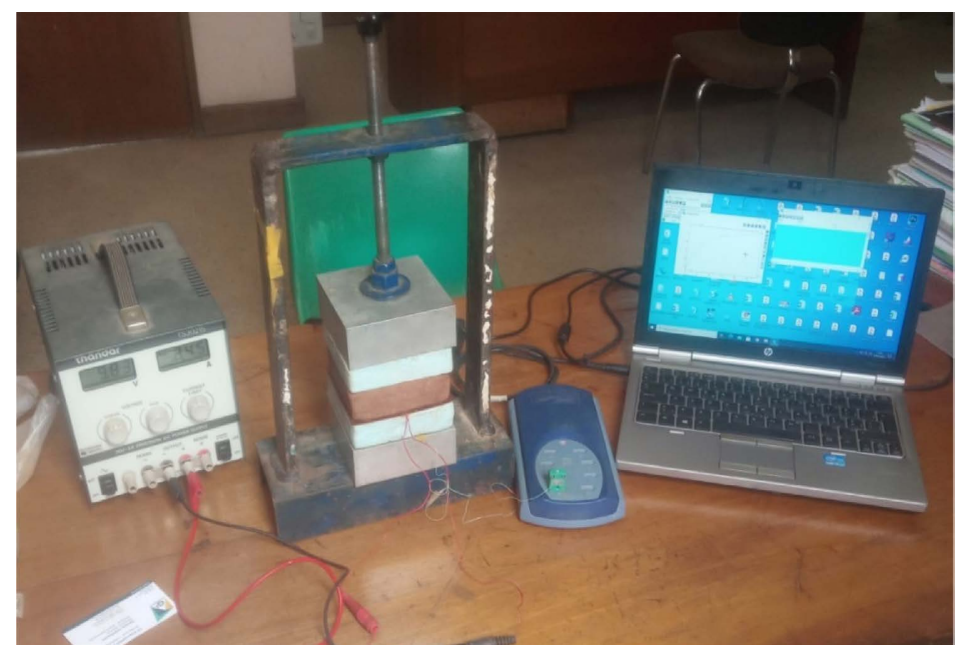

Figure 5. Asymmetrical hot plane experimental setup. 


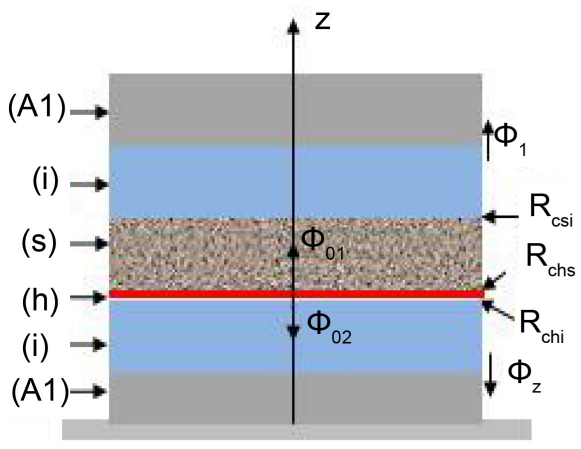

(Al) : Aluminium block, (i) : insolent block, (s): sample with plastic bag, (h): heating element

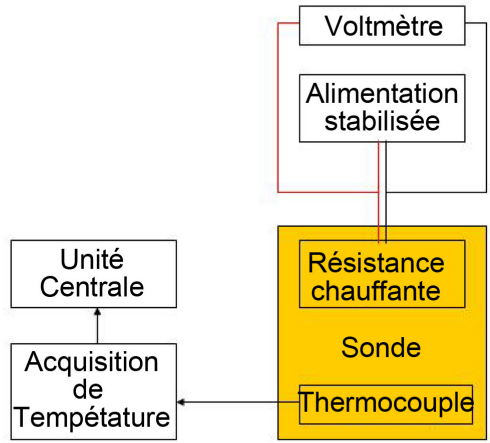

Figure 6. Asymmetrical hot plane experimental device (cross-sectional view) and combination of equipment.

set-up is placed on an isothermal block (made of aluminum) with a thickness of $2 \mathrm{~cm}$ and a cross-section of $20 \mathrm{~cm} \times 20 \mathrm{~cm}$. The temperature $\left(T_{0}\right)$ of this isothermal block is assumed to be uniform. This assumption is validated if the $B_{i}=\frac{h \cdot L}{\lambda_{A l}}$ Biot number is less than $0.1[18]$.

Indeed, considering a convection coefficient $h=10 \mathrm{Wm}^{-2} \mathrm{~K}^{-1}$, the thermal conductivity of the $\mathrm{Al}$ blocks $\lambda=200 \mathrm{Wm}^{-1} \mathrm{~K}^{-1}$ leads to $B_{i}=0.01$, i.e. the temperature of the aluminum blocks can be considered as uniform.

A heat flow step (thermal power $P=U I$ ) is then applied by means of a voltage generator (stabilized power supply 0 - $30 \mathrm{~V}$ : see Figure 4) and the evolution of the temperature $T_{s}(t)$ at the centre of the probe is measured by means of the Picolog probe (see Figure 4). During the time when the disturbance has not reached the other faces, the heat transfer at the centre of the sample can be considered as unidirectional.

\section{D Quadrupole Modelling}

Since the transverse dimensions of the resistor are large compared to the thickness of the sample, the heat transfer can be assumed to remain unidirectional at the centre of the probe and modelled using the quadrupole method [19] [20] [21]. With this assumption, the temperature at the centre of the heating element depends only on the z-coordinates and the time $t$

\section{1) $1 \mathrm{D}$ model for a semi-infinite model}

Here, we will consider the probe as a thin system (the temperature will then be uniform over the entire thickness of the probe).

- The thermal quadrupole method applied to the sample for the upward flow is written:

$$
\left(\begin{array}{c}
\theta_{0} \\
\Phi_{01}
\end{array}\right)=\left(\begin{array}{cc}
1 & 0 \\
\rho_{s} c_{s} e_{s} p & 1
\end{array}\right)\left(\begin{array}{cc}
1 & S R_{c s e} \\
0 & 1
\end{array}\right)\left(\begin{array}{c}
\theta_{3} \\
E \sqrt{p} \theta_{3}
\end{array}\right)
$$

- The quadrupole method applied for the downward flow is written by also considering the insulator as a semi-infinite material: 


$$
\left(\begin{array}{c}
\theta_{0} \\
\Phi_{02}
\end{array}\right)=\left(\begin{array}{cc}
1 & S R_{c s i} \\
0 & 1
\end{array}\right)\left(\begin{array}{c}
\theta_{4} \\
E_{i} \sqrt{p} \theta_{4}
\end{array}\right)
$$

$\theta_{0}=L\left(T_{0}(x, t)\right)$ is the Laplace transform of the temperature rise at the probe $T_{S}(t)=T_{0}(t)-T(0) ; \Phi_{01}=L\left(\phi_{0}(x, p)\right)$ is the Laplace transform of the heat flux density dissipated in the sample upwards; $\Phi_{02}$ is the Laplace transform of the heat flux density dissipated in the sample downwards. $R_{c s e}$ is the contact resistance at the probe/sample interface, $R_{c e i}$ is the contact resistance at the sample/insulator interface, $R_{c s i}$ is the contact resistance at the probe/insulator interface.

The total flux density is given by the relation

$$
\Phi_{0}=\Phi_{1}+\Phi_{2}
$$

Combining all these different matrices, we arrive at the relationship that represents the theoretical response of the asymmetric semi-infinite hot plane model in Laplace space [22]:

$$
\theta_{c}(x, p)=\frac{\phi_{0} S}{p} \cdot \frac{1}{\frac{\rho_{s} c_{s} e_{s} S p+\left(1+R_{c h s} \rho_{s} c_{s} e_{s} S p\right) E S \sqrt{p}}{1+R_{c h s} E S \sqrt{p}}+\frac{E_{i} S \sqrt{p}}{1+R_{c h i} E S \sqrt{p}}}
$$

A simplified estimation at long times (simplified model), of the Relation (4) allows to obtain in real space.

$$
\Delta T(0, t \rightarrow \infty)=\phi_{0} S\left(\frac{E^{2} R_{c h s}+E_{i}^{2} R_{c h i}}{\left(E+E_{i}\right)^{2}}-\frac{\rho_{s} c_{s} e_{s}}{S\left(E+E_{i}\right)^{2}}\right)+\frac{2 \phi_{0}}{\left(E+E_{i}\right) \cdot \sqrt{\pi}} \sqrt{t}
$$

The numerical calculation of the slope $\alpha$ of the curve $T=f\left(t^{1 / 2}\right)$, which allows to obtain a pre-estimate (preest) of the thermal effusivity of the material given by the Relation (6).

$$
E_{\text {preest }}=\frac{2 \phi_{0}}{\beta \sqrt{\pi}}-E_{i}
$$

The volumetric heat capacity $\rho C_{p}$ can also be pre-estimated from the simplified model. The heat transfer $\delta q$ through the probe during an $d t$ infinitesimally small time interval corresponds to a heat flow $\rho_{0}=\frac{\delta q}{d t}$, which causes a temperature rise $d T$ in the probe. By exploiting the linear part of the thermogram $T=f(t)$, its slope $\beta$ can be calculated numerically and thus the pre-estimated value of the volume heat capacity of the sample can be deduced by the relationship:

$$
\left(\rho C_{p}\right)_{\text {preest }}=\frac{\frac{\phi_{0}}{\beta}-\rho C_{p i} e_{i}-\rho C_{p s} e_{s}}{e}
$$

The pre-estimates of $E$ and $\rho C_{p}$ will allow us to determine the apparent thermal conductivity of the materials by the Relation (8).

$$
\lambda_{\text {prest }}=\frac{\left(E^{2}\right)_{\text {preest }}}{\left(\rho C_{p}\right)_{\text {preest }}}
$$




\section{2) Asymmetric 1D quadrupole models for the complete model Temperature at the centre of the probe}

Still considering the diagram in Figure 5, applying the quadrupole formalism [23], for:

- for the upward flow:

$$
\begin{aligned}
\left(\begin{array}{c}
\theta_{0} \\
\Phi_{01}
\end{array}\right) & =\left(\begin{array}{cc}
1 & 0 \\
\rho_{s} c_{s} e_{s} p & 1
\end{array}\right)\left(\begin{array}{cc}
1 & S R_{c s e} \\
0 & 1
\end{array}\right)\left(\begin{array}{cc}
A_{e} & B_{e} \\
C_{e} & D_{e}
\end{array}\right)\left(\begin{array}{cc}
1 & S R_{c e i} \\
0 & 1
\end{array}\right)\left(\begin{array}{cc}
A_{i} & B_{i} \\
C_{i} & D_{i}
\end{array}\right)\left(\begin{array}{c}
\theta_{5} \\
\Phi_{5}
\end{array}\right) \\
& =\left(\begin{array}{ll}
A & B \\
C & D
\end{array}\right)\left(\begin{array}{c}
\theta_{5} \\
\Phi_{5}
\end{array}\right)
\end{aligned}
$$

With: $A_{\mathrm{e}}, B_{\mathrm{e}} C_{e}$ and $D_{e}$ the elements of the matrix representing the material to be characterized:

$$
\begin{aligned}
& A_{e}=\cosh \left(q_{e} \cdot e\right), \quad B_{e}=\frac{\sinh \left(q_{e} \cdot e\right)}{\lambda_{e} \cdot q_{e}} \\
& C_{e}=\lambda_{e} \cdot q_{e} \cdot \sinh \left(q_{e} \cdot e\right), \quad D_{e}=A_{e}
\end{aligned}
$$

And $A_{i}, B_{i}, C_{i}$ and $D_{i}$ are the matrix elements representing the material to be characterized:

$$
\begin{aligned}
& A_{i}=\cosh \left(q_{i} \cdot e_{i}\right), \quad B_{i}=\frac{\sinh \left(q_{i} \cdot e_{i}\right)}{\lambda_{e} \cdot q_{i}} \\
& C_{i}=\lambda_{i} \cdot q_{i} \cdot \sinh \left(q_{i} \cdot e_{i}\right), \quad D_{i}=A_{i}
\end{aligned}
$$

- for the downstream

$$
\left(\begin{array}{c}
\theta_{0} \\
\Phi_{02}
\end{array}\right)=\left(\begin{array}{cc}
1 & S R_{c s i} \\
0 & 1
\end{array}\right)\left(\begin{array}{cc}
A_{i} & B_{i} \\
C_{i} & D_{i}
\end{array}\right)\left(\begin{array}{c}
\theta_{4} \\
\Phi_{4}
\end{array}\right)
$$

Combining Relations (3), (9) and (12), we then obtain the expression for the temperature at the centre of the probe in Laplace space, given by Relation (13):

$$
\theta_{0}(x, p)=\frac{\phi_{0}}{p} \cdot \frac{1}{\frac{D}{B}+\frac{D_{i}}{B_{i}+R_{c s i} D_{i}}}
$$

The Levenberg-Marquart (1944) algorithm [24], associated with the De Hoog algorithm [25]: integrated in a Matlab code, allows us to estimate the value of $E$ that minimizes the sum of the squared errors of the functional $\psi$, between the experimental $\Delta T_{\text {exp }}(t)=T(0, t)-T_{a}$ and theoretical curves.

$$
\psi=\sum_{i=1}^{n}\left[\Delta T_{\text {exp }}\left(t_{i}\right)-T_{\text {model }}\left(t_{i}\right)\right]^{2}
$$

\subsection{Experimental Device for Mechanical Characterisation}

The choice of the type of building material (earth, sand, laterite, cement...) with which to build should not be arbitrary. Knowledge of parameters such as grain size, compressive and flexural strength, water absorption rate and even environmental guarantees are essential to ensure comfort for future inhabitants. One aspect of our work in this research is the mechanical characterization of po- 
to-poto blocks as infill materials (wall elevation). According to the literature [6], the compressive strength for a conventional material (breeze block of dimensions $29.5 \mathrm{~cm} \times 14 \mathrm{~cm} \times 11 \mathrm{~cm}$ ) is between $0.2 \mathrm{MPa}$ and $0.6 \mathrm{MPa}$.

\subsubsection{Bending Behaviour of Our Material}

The principle here is to apply a bending force to a sample. This load causes the sample to be crushed. At the same time, the deformation stresses are measured during the test.

Bending characterizes the resistance to deformation of the material when it is subjected to stress. It is due to a force acting perpendicular to the axis of a construction element resting on supports at its ends: two cylindrical tubes for example. The experimental setup shown in Figure 7 and Figure 8 is used here.

If $F(\mathrm{~N})$ is the bending load of the specimen (measured by CONTROLS.CAT machine $\mathrm{N}^{\circ} \mathrm{T} 1004$, Mat No. 3558), $D=50 \mathrm{~mm}$ the distance of the cylindrical supports, $2 L=80 \mathrm{~mm}$ the length of the block and $h=20 \mathrm{~mm}$ the average thickness of the block. We determined the bending strength in MPa by the formula [6].

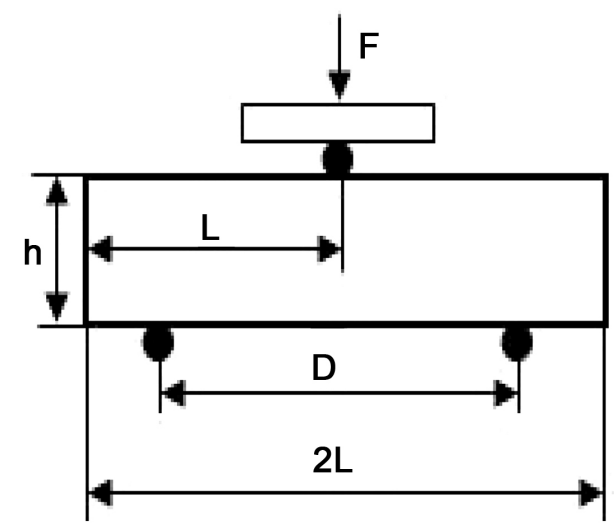

Figure 7. Experimental setup in bending.

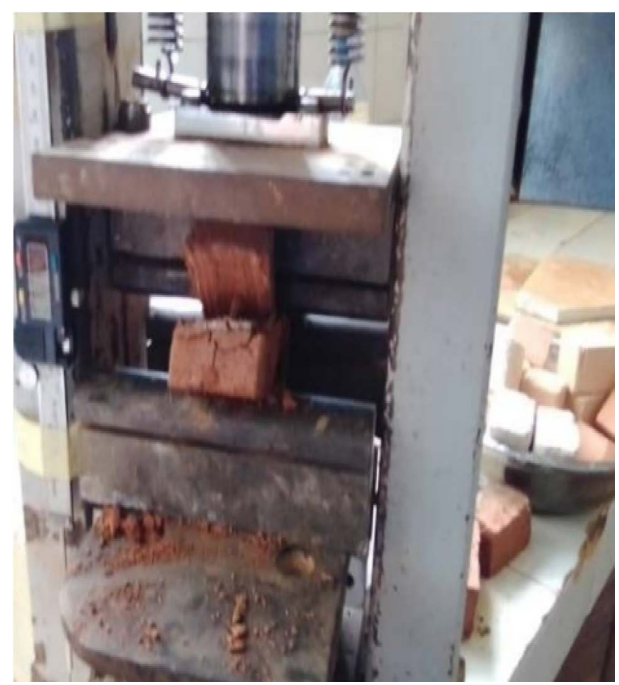

Figure 8. Hydraulic press. 


$$
R_{f}=\frac{3 F D}{2 L h^{2}}
$$

The knowledge of the bending strength will allow us to determine the Young's modulus by the relation:

$$
E=\frac{R_{f}}{\varepsilon} \text { avec } \varepsilon=\frac{\Delta L}{L_{0}}
$$

where $\varepsilon$ is the deformation.

\subsubsection{Compressive Behaviour of the Material}

Compression is the load caused by the action of two equal and opposite forces acting on the same line parallel to the axis of the element and tending to shorten it. The experimental setup is shown in Figure 9.

If $F$ is the compressive breaking load (measured in the upward reading by the CONTROLS No. 4117 ring machine, $F_{\max }=30,000 \mathrm{~N}$ ), we have obtained the stress $R_{c}$ from the relationship [6].

$$
R_{f}=\frac{F}{h^{2}}
$$

\section{Experimental Results}

The determination of thermal conductivity is carried out in several steps.

\subsection{Experimental Temperature Graphs}

A temperature step $P=U I$ is sent through the generator (Figure 4 ). This gives a temperature rise at the centre of the probe recorded by the thermocouple. Figure 10 shows the experimental temperature graphs for the poto-potoat $0 \%$ and $4 \%$. The exploitation of these thermograms, by making a linear regression with Excel, could already allow us to consider values of $\lambda_{\text {exp }}$. We can already notice here the influence of the addition of fibers on the evolution of the temperature, insofar as if we observe the inertia of the probe at the beginning of the recording,

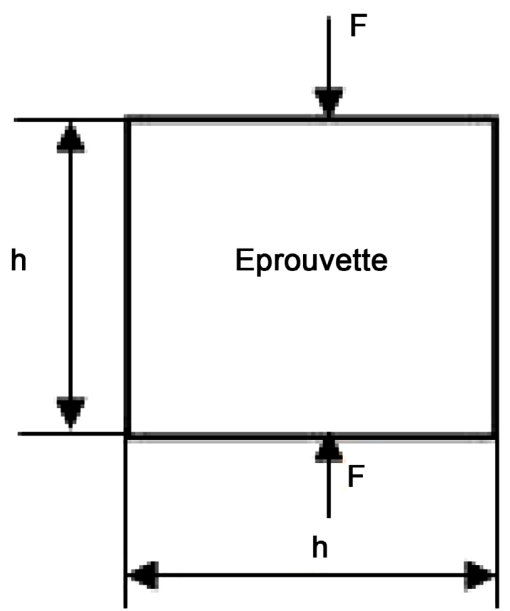

Figure 9. Compression experiment. 


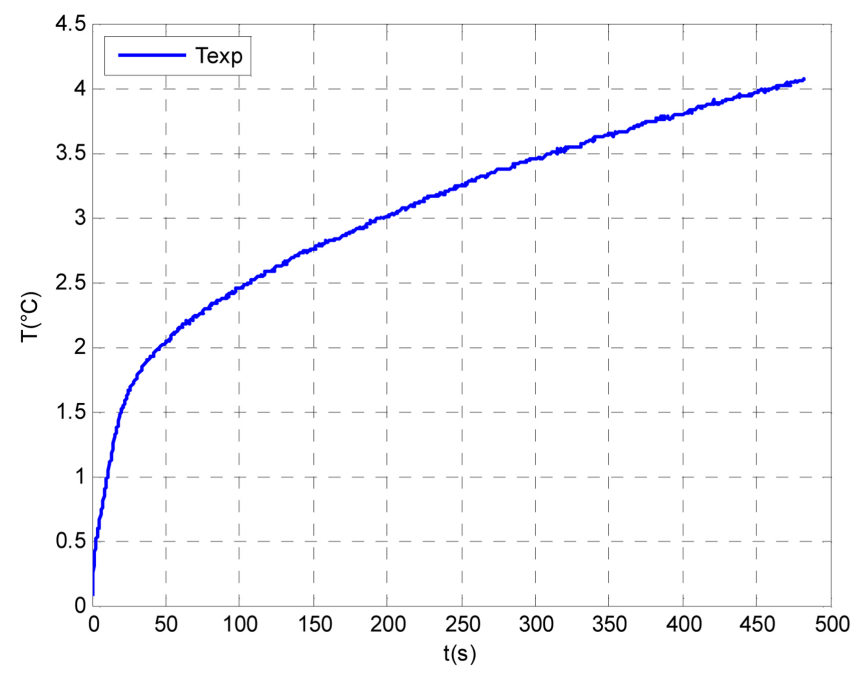

(a)

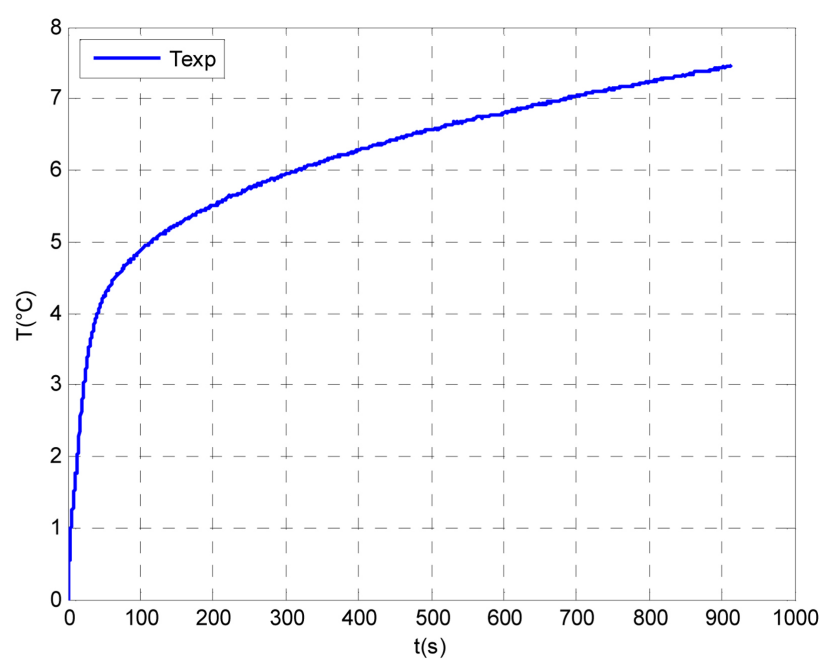

(b)

Figure 10. Experimental temperature graph for poto-poto (a) $0 \%$; (b) $4 \%$.

we notice on Figure 10(b) that the thermal flow takes more time to propagate to the centre of the material, contrary to the material with the addition of $4 \%$ of fibers. One explanation for this may be that the addition of the fibers probably creates a non-negligible porosity compared to the compact material.

\subsubsection{Pre-Estimation of $E$ and $\rho C_{p}$ : Thermogram of Temperatures Obtained with the Simplified Model}

We have represented the thermograms of experimental temperatures (blue); model temperatures (red) and temperatures of the semi-infinite medium hypothesis (green). By analysing these thermograms, it can already be observed that the thermograms for the $T_{\text {semintini } i}$ semi-infinite medium hypothesis and the $T_{\text {exp }}$ model hypothesis are superimposed up to 400s (Figure 10). This indicates that an evaluation of the slope $\alpha$ of the thermogram $T=f\left(t^{1 / 2}\right)$ (Figure 11), can allow a good pre-estimation of the thermal effusivity between 100 and 150s. Moreover, when a linear regression of the slope is performed for the experimental thermogram (Figure 11: red curve), it can be observed that the curve is tangent to the slope in this time interval. In the same way, the exploitation of the linear part of the thermogram $T=f(t)$ can allow a good pre-estimation of the volumetric heat capacity between 300 and $400 \mathrm{~s}$. It is also observed that this model does not minimize the sum of the quadratic differences between $T_{\exp }$ and $T_{\text {seminnfini }}$ This justifies the need for the full model study.

The truest value of the thermal conductivity can only be validated if there is agreement between the experimental results (thermogram $T_{\text {exp }}=f\left(t^{1 / 2}\right)$ and $T_{\text {exp }}=f(t)$ Equation (4)) and the developed model (Equation (14)), the acceptable relative deviation being $8 \%$. The modelling of the device (Equation $(14))$ then imposes input values $\left(E_{\text {prest }}\right.$ Equation (6) and $\left(\rho C_{p}\right)_{\text {prest }}$ Equation (7)). By a convergence criterion, we will then determine the true value of $\lambda$ which will be compared to the estimated value. 


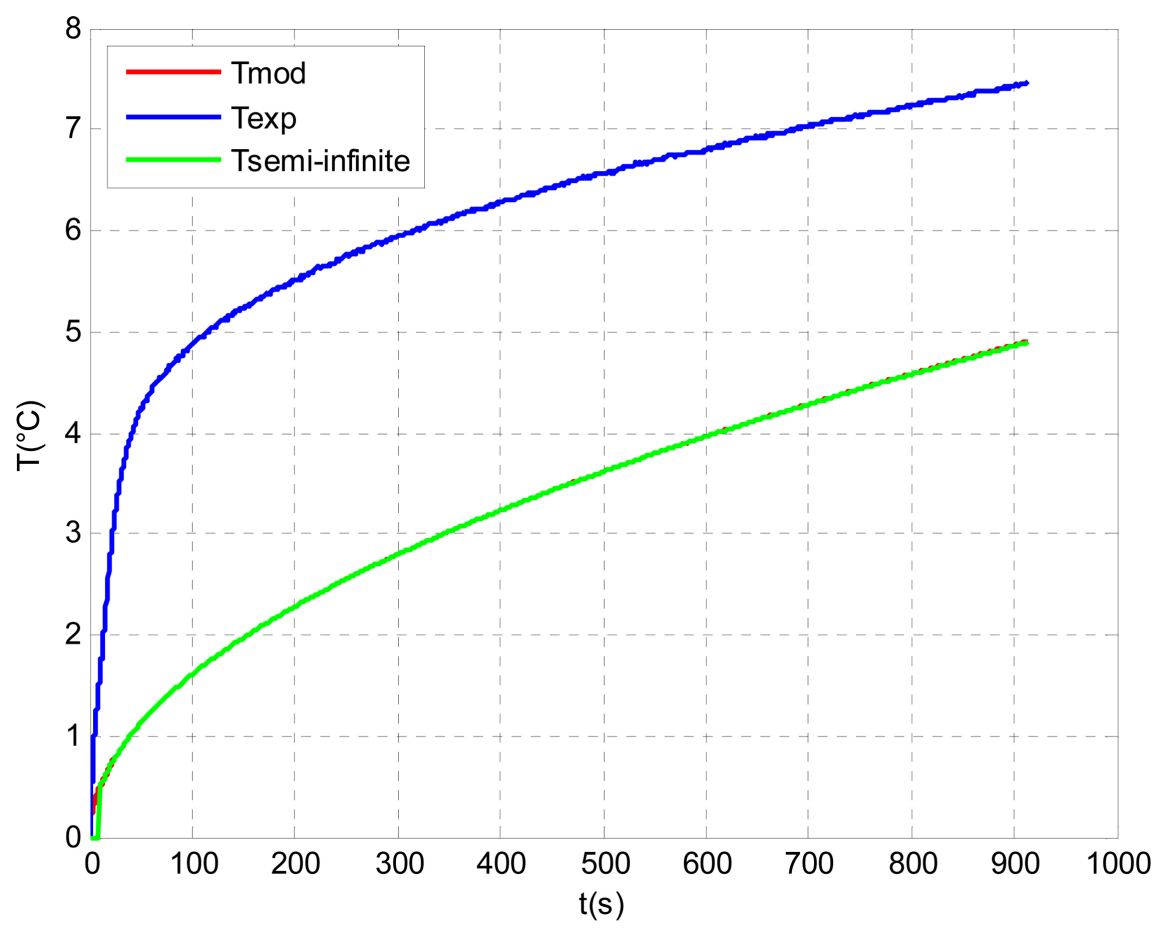

Figure 11. Temperature thermograms obtained from experimental data and simplified model equations.

In the perspective of the validation of the obtained results, it is also important to check whether there is a definite deceleration between the values to be estimated and in the estimation intervals. The reduced sensitivity curves (Figure 12) justify that the developed model is indeed sensitive to the thermal effusivity $E$ and the volumetric heat capacity $\rho \mathrm{C}_{\mathrm{p}}$.

As the reduced sensitivities of these two parameters are not correlated, there is a correlation of the thermal contact resistance, which is justified as the effective clamping device tends to zero contact resistance. Looking at the $T_{\text {seminfini }}=f(t)$ curve in Figure 11, we can see that due to its thermal inertia at the beginning of the recording, there is a correlation between the residual curve of $\rho C_{p}$ (black curve) and that of the thermal resistance (blue curve), which is why its estimation can only be done at long times (between 300 and 400 s) when the decorrelation is quite obvious.

\subsubsection{Estimation from the Full Model}

A numerical simulation with the complete model, taking as initial values of $E$ and $\rho C_{p}$ (Equation (14) and Equation (16)) those pre-estimated from the simplified model, shows well that there is convergence (Figure 13) between the experimental temperatures and the model temperature (obtained after numerical inversion of the Relation (14)). This convergence is also confirmed by the reduced sensitivity curve as shown in Figure 14.

The thermograms $T=f(t)$ obtained from the full model for the $0 \%, 4 \%$ and 6\% samples are presented below in Figures 15-20 together with their reduced 


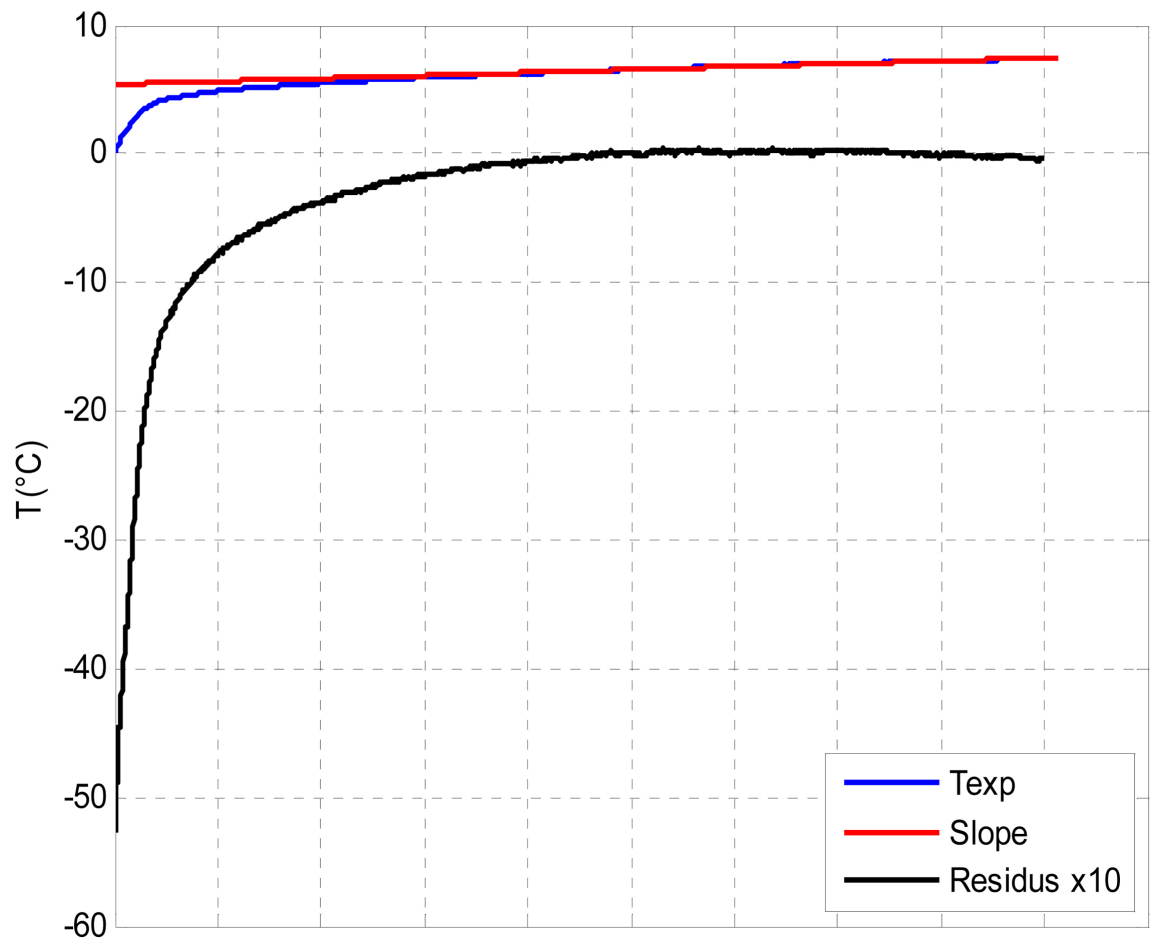

Figure 12. Linear regression of the slope of the experimental thermogram.

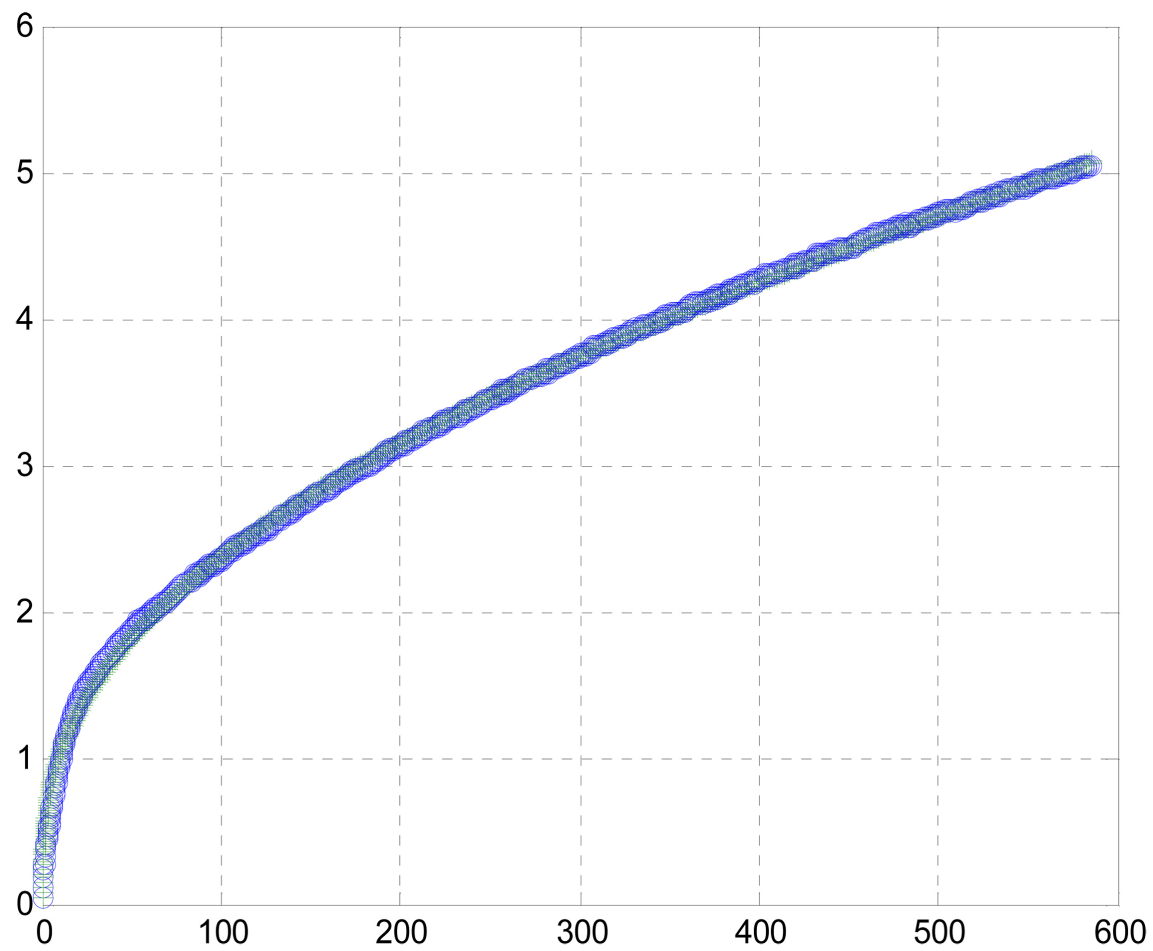

Figure 13. Convergence criterion.

sensitivities to the parameters $E, \rho C_{p}$ and $S R_{c}$.

The first analysis that can be made from these thermograms reveals that the complete model minimizes the square deviations between the experimental curve 


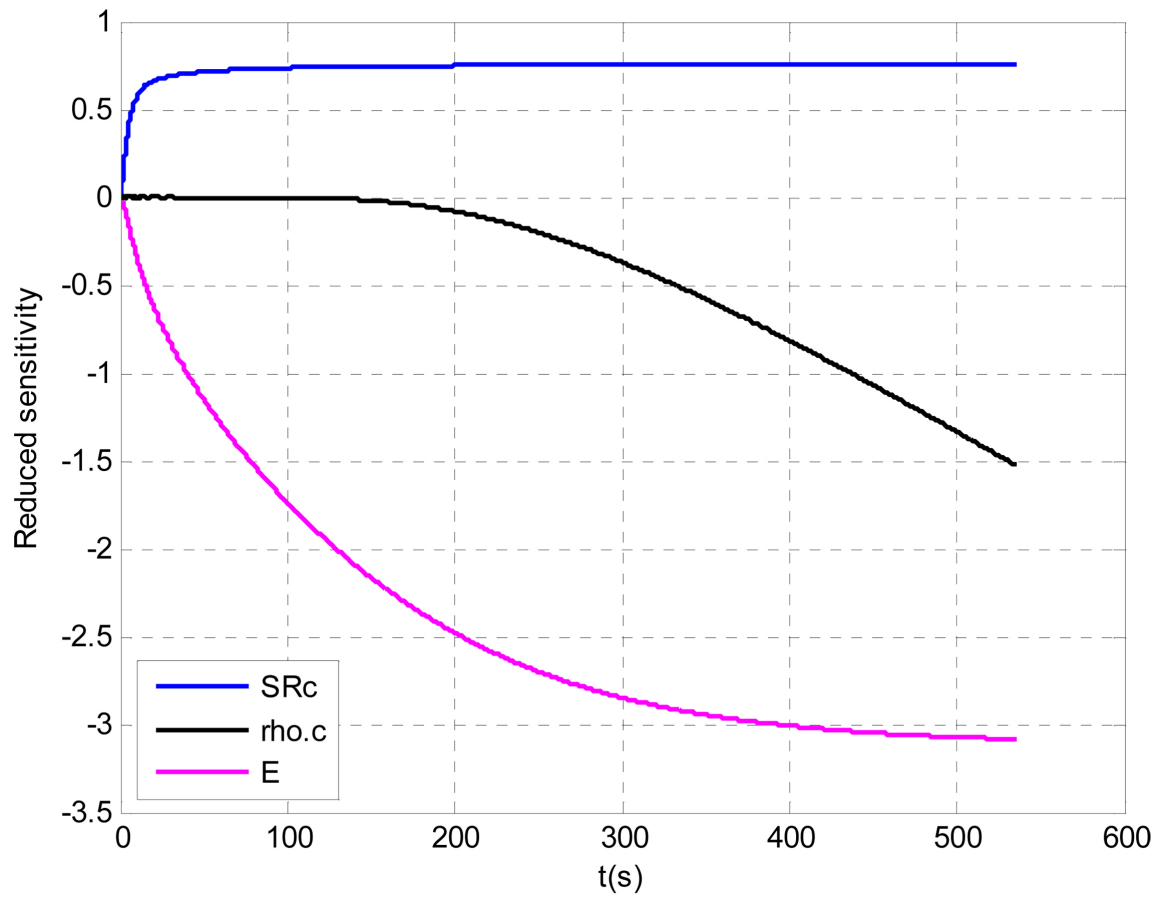

Figure 14. Reduced sensitivity curve: poto-poto at $6 \%$.

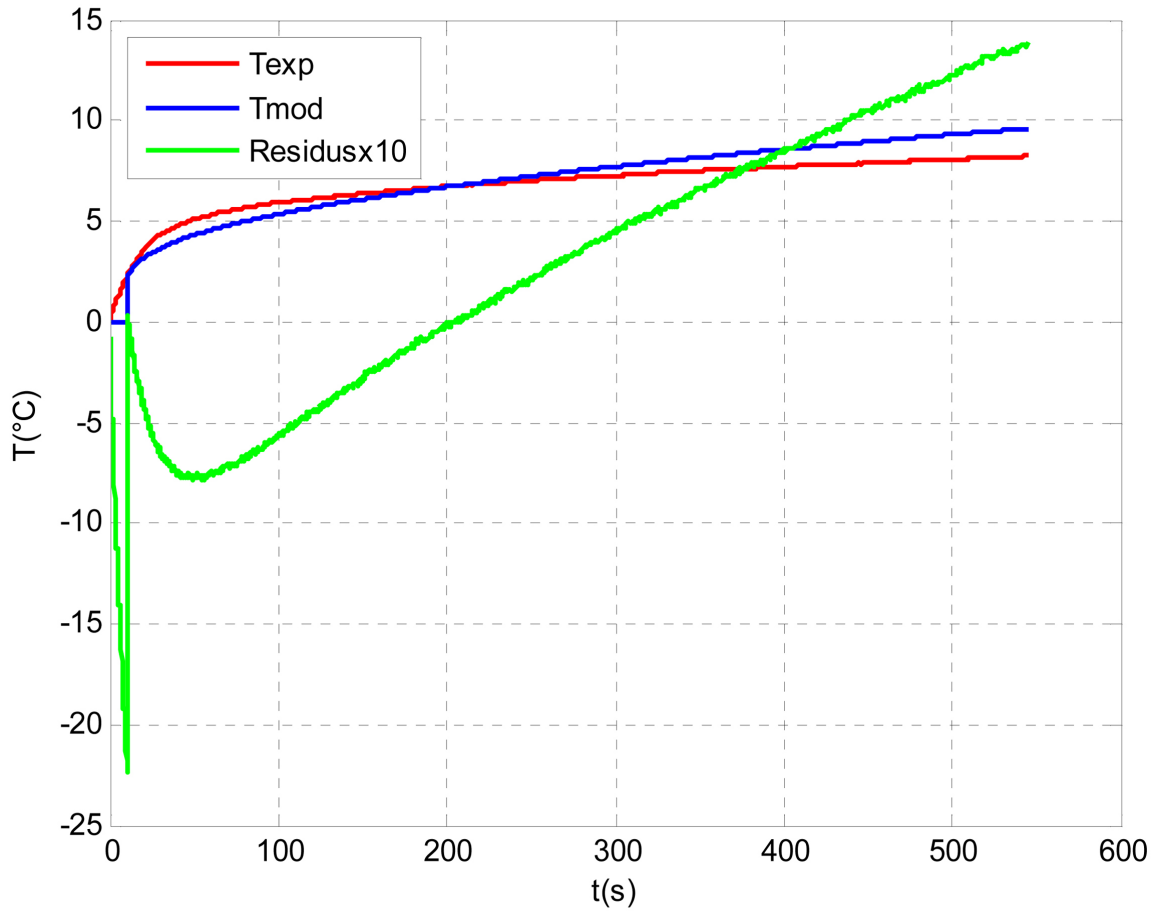

Figure 15. Thermograms of temperatures $T=f(t)$ and residuals obtained from the complete $0 \%$ bamboo fiber model.

and the model curve. For the reference material ( $0 \%$ fiber), we observe that the quadratic differences between $T_{\exp }$ and $T_{\bmod }$ are still quite high. The residual curve (Figure 15: green curve) further justifies this, as we have very high biases around zero. 


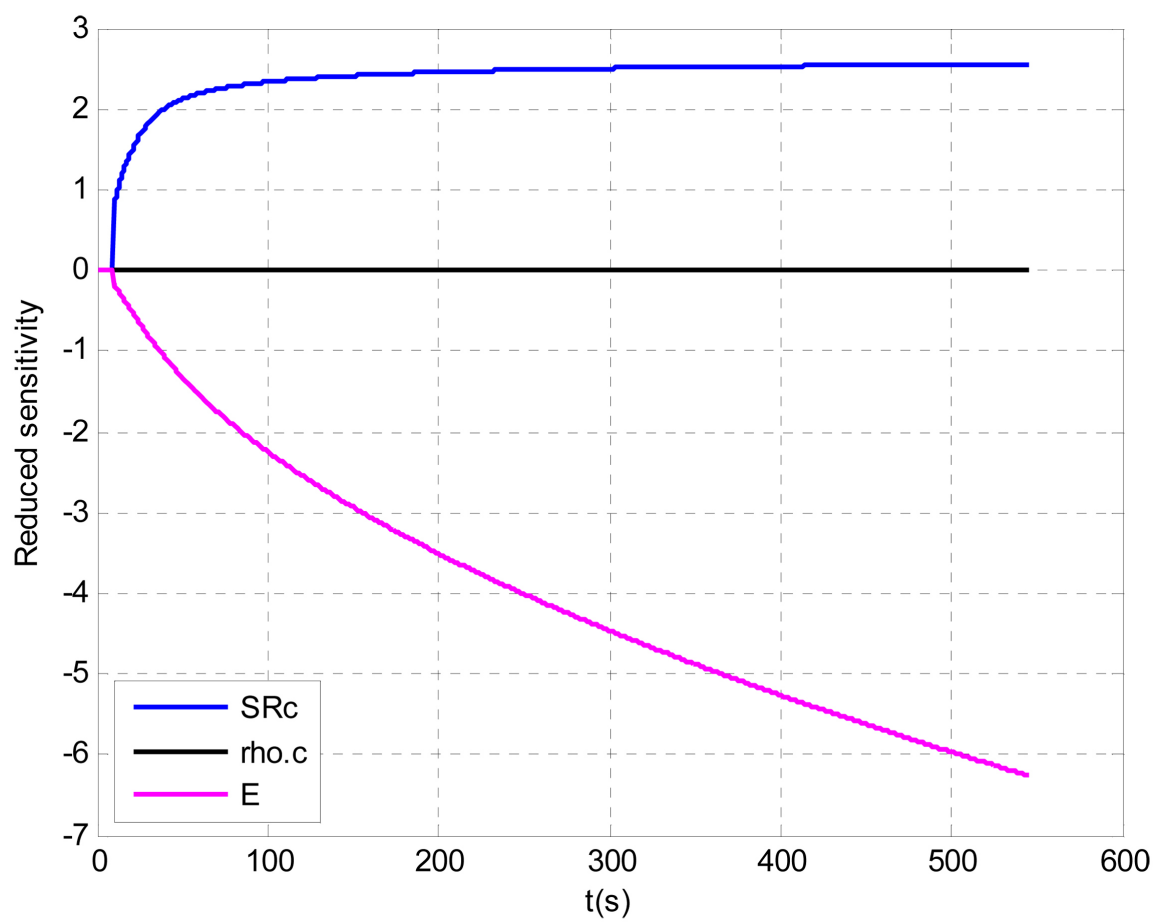

Figure 16. Curve of reduced sensitivities to parameters at $0 \%$ bamboo fiber.

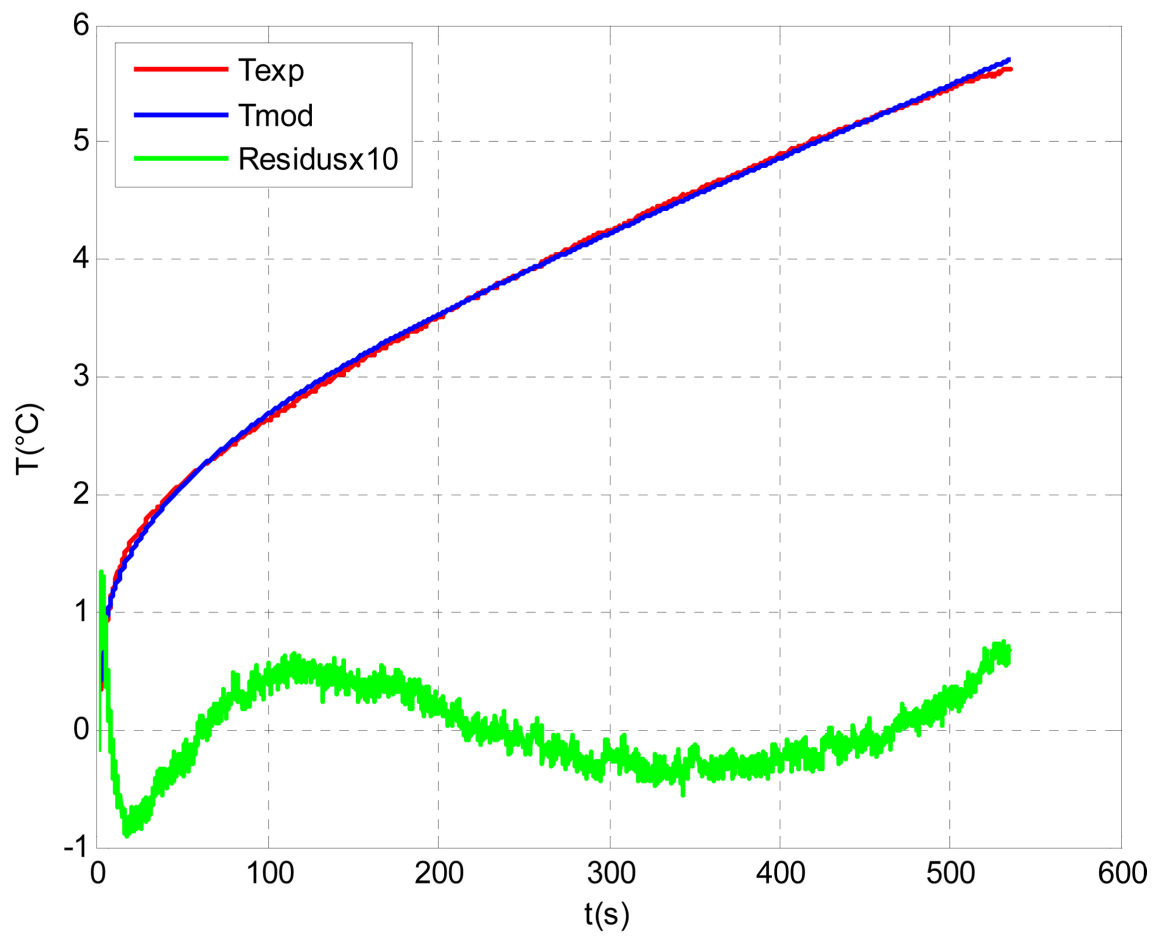

Figure 17. Thermograms of temperatures $T=f(t)$ and residuals obtained from the complete $4 \%$ bamboo fiber model.

Also, strong correlations of the parameters with reduced sensitivities are observed (Figure 15). This can be justified, as the soil used is not lateritic and therefore has a very low porosity. Another reason that could justify this 


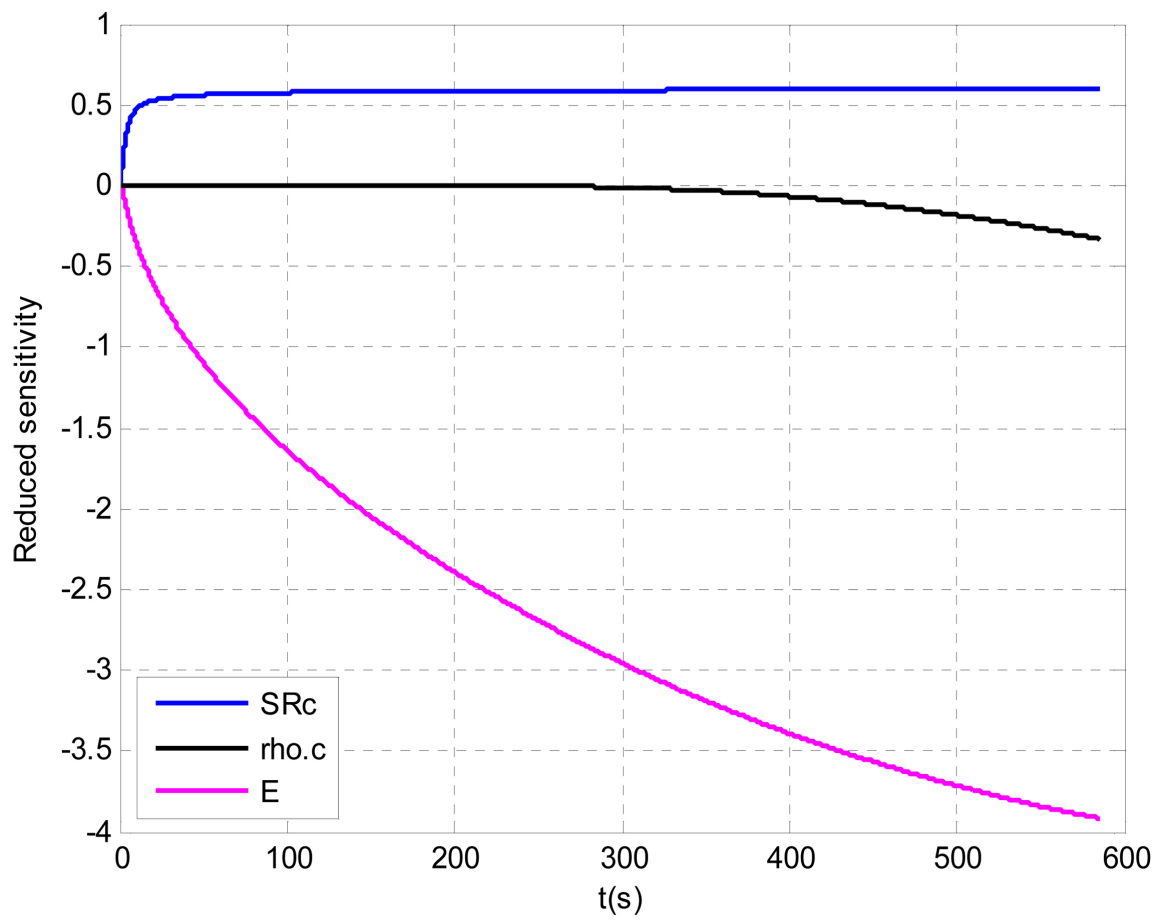

Figure 18. Curve of reduced parameter sensitivities at $4 \%$ bamboo fibre.

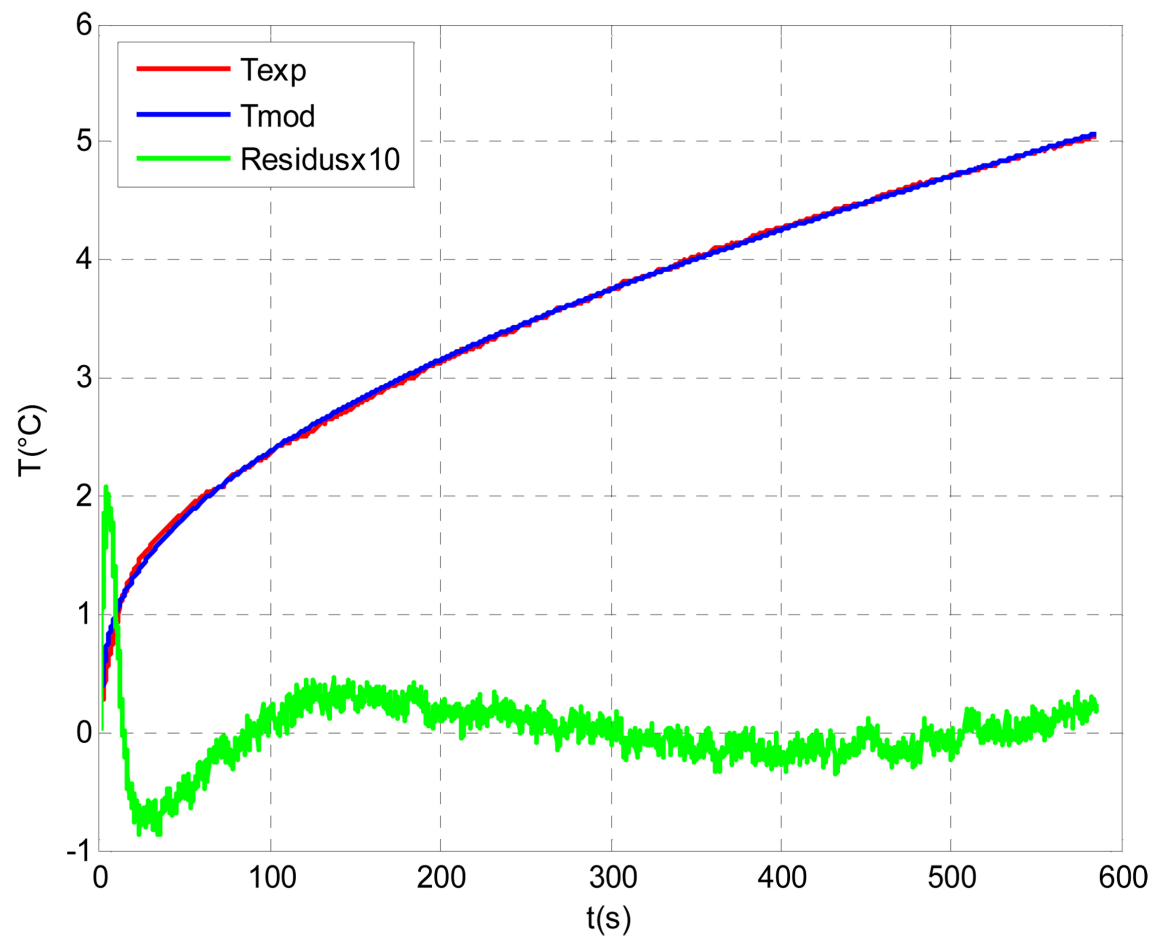

Figure 19. Thermograms of temperatures $T=f(t)$ and residuals obtained from the complete $6 \%$ bamboo fiber model.

non-convergence of the estimation residuals between $T_{\text {exp }}$ and $T_{\text {est }}$ is the quality of the material. As can be seen in Figure 4(a), we have multiple cracks. These are due to the slow shrinkage of the water in the material during the period of 


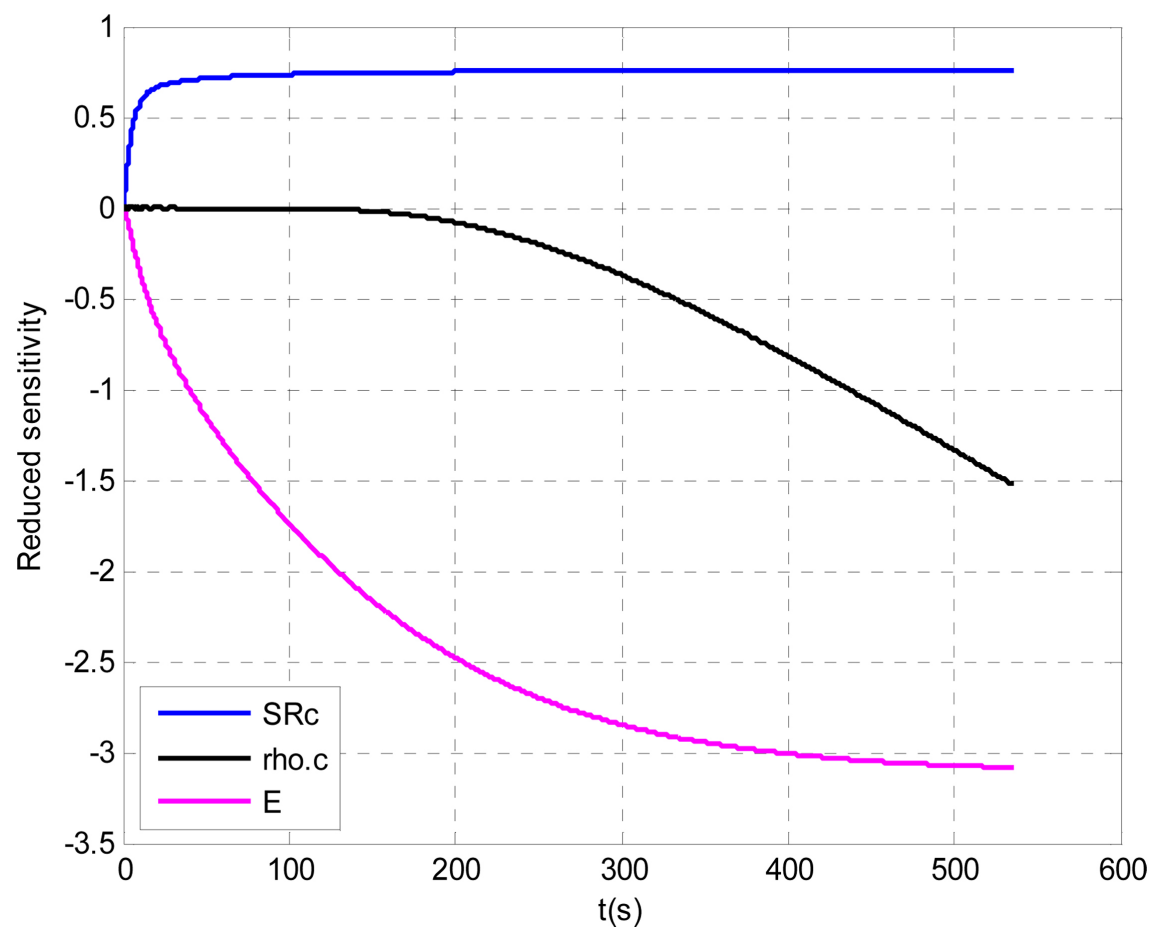

Figure 20. Curve of reduced parameter sensitivities at $6 \%$ bamboo fibre.

cleaning. The appearance of these cracks does not favour the diffusion of the heat flux in the centre of the probe, creating very quickly $2 \mathrm{D}$ and $3 \mathrm{D}$ transfers around the centre of the sample.

A clear improvement in the residual curve (Figure 16 and Figure 18) can be seen as the bamboo fibers are added to the material. Similarly, a decorrelation of the parameters $E$ and $\rho C_{p}$ is observed on the reduced sensitivity curve. In Figure 18 , a clear improvement of the residuals is observed, but the inertia of the probe is still very high (around $100 \mathrm{~s}$ ). This requires a very long heating time. The analysis of the residual curves justifies the fact that although the thermograms $T=f(t)$ and $T_{\text {exp }}=f(t)$ are superimposed up to $400 \mathrm{~s}$ (Figure 16 and Figure 18 ), a good estimation of the parameters can only be made between 300 and 400 $s$ (for Figure 16) and between 500 and 550 s (for Figure 18).

Note that a good estimate of the thermal conductivity by the full model is reliable when there is a relative difference $\left(\frac{\Delta \lambda}{\lambda}\right)$ between $\lambda_{\text {prest }}$ (Equation (8)) and $\lambda_{\text {est }}$ (Equation (14)) of less than $8 \%$ [18].

\subsection{Summary Table of Measured Thermal and Mechanical Parameters}

The experimental thermal and mechanical parameters obtained are presented in Table 3 opposite.

The experimental results of the thermal conductivity obtained show that the addition of the fibers has a strong influence on the insulating properties of this material. The thermal conductivity decreases with the addition of the bamboo 
Table 3. Experimental characterization results.

\begin{tabular}{cccccccccccc}
\hline & $\begin{array}{c}\text { Simplified } \\
\text { model }\end{array}$ & $\begin{array}{c}\text { Complete } \\
\text { model }\end{array}$ & $\begin{array}{c}\text { Simplified } \\
\text { model }\end{array}$ & $\begin{array}{c}\text { Complete } \\
\text { model }\end{array}$ & $\begin{array}{c}\text { Simplified } \\
\text { model }\end{array}$ & $\begin{array}{c}\text { Complete } \\
\text { model }\end{array}$ & Difference & $R_{c}$ & $R_{f}$ & $E_{l}$ \\
& $\begin{array}{c}E \\
\left(\mathrm{~J} \mathrm{~m}^{-2} \mathrm{~K}^{-1} \mathrm{~s}^{-1 / 2}\right)\end{array}$ & $\begin{array}{c}E \\
\left(\mathrm{~J} \mathrm{~m}^{-2} \mathrm{~K}^{-1} \mathrm{~s}^{-1 / 2}\right)\end{array}$ & $\rho C_{p}\left(\mathrm{~J} \mathrm{~m}^{-3} \mathrm{~kg}^{-1}\right)$ & $\rho C_{p}\left(\mathrm{~J} \mathrm{~m}^{-3} \mathrm{~kg}^{-1}\right)$ & $\lambda\left(\mathrm{W} \mathrm{m}^{-1} \mathrm{~K}^{-1}\right)$ & $\lambda\left(\mathrm{W} \mathrm{m}^{-1} \mathrm{~K}^{-1}\right)$ & $\frac{\Delta \lambda}{\lambda}(\%)$ & $\mathrm{MPa}$ & $\mathrm{MPa}$ & $\mathrm{MPa}$ \\
\hline $0 \%$ & 1484.82 & 1506.96 & $2,070,088$ & $2,070,000$ & 1.065 & 1.097 & 3.009 & 5.25 & 0.82 & \\
$2 \%$ & 1408.58 & 1422.36 & $2,056,237$ & $2,059,776$ & 0.965 & 0.982 & 1.791 & 6.78 & 2.90 & 20.62 \\
$4 \%$ & 1330.21 & 1443.27 & $2,160,000$ & $2,160,036$ & 0.819 & 0.964 & 17.719 & 7.42 & 5.95 & 50.60 \\
$6 \%$ & 2001.15 & 1921.46 & $5,680,048.13$ & $5,680,013.13$ & 0.705 & 0.650 & 7.805 & 5.94 & 8.26 & 79.42 \\
\hline
\end{tabular}

$E$ : thermal effusivity, $\lambda$ : thermal conductivity, $\rho C_{p}$ : bulk heat capacity, $E_{\text {f }}$ modulus of elasticity, $R_{c}$ compressive strength, $R_{f}$ flexural strength.

fibers as can be seen in Figure 19.

Although the various values of thermal conductivity obtained are higher than those of pozzolan-based breeze blocks $\left(0.54 \mathrm{Wm}^{-1} \mathrm{~K}^{-1}\right)[23]$ :, it should be noted that our samples with $6 \%$ fiber content have a thermal conductivity lower than that of the sand breeze block agglomerates $\left(1.12 \mathrm{Wm}^{-1} \mathrm{~K}^{-1}\right)$ [26] commonly used in Cameroon, particularly in the Central zone. Therefore, at this content (6\% fiber), the material obtained can be considered as a thermal insulator and therefore its use as a filling material for the building envelope would be beneficial in terms of energy saving during air conditioning processes.

It should also be noted that with its high thermal inertia $\left(5,680,048.13 \mathrm{Jm}^{-3}\right.$ $\mathrm{kg}^{-1}$ ), it can greatly contribute tothephenomenon of night-time ventilation.

Furthermore, from a mechanical point of view, the MIPROMALO (Mission de Promotion des Matériaux Locaux) recommends, for filling materials, a 7-day contact compressive strength greater than $2 \mathrm{MPa}$ [3] [16]. However, for these materials used as filling materials and not for load-bearing structures, compressive strengths such as $0.6 \leq R_{c} \leq 1 \mathrm{MPa}$ are accepted.

The experimental results obtained for the compressive strengths of our samples show that the addition of the fibers helps to optimize the hardness of our installed material. Their compressive strengths are in line with the standards required for building envelope fillers [14] [15]. The addition of the bamboo fibers therefore strengthens the cohesion of the soil and at the same time increases its compressive strength (see Figure 21).

It is noticeable that above $6 \%$ fiber addition, the compressive strength of the material decreases. This observation can be justified insofar as we have noticed that at more than $6 \%$ of bamboo fiber, the proportion of fibersis much too high, the material during its curing period bulges and therefore cracks rapidly due to the small amount of soil. It should also be noted that the fibers have been placed longitudinally in the material, which tends to make it more flexible. This is confirmed by the fact that if we observe the evolution of the bending strength, it increases with the addition of the fibers. The addition of the fibers therefore contributes to ensuring that the composite material does not break quickly when 


$$
\begin{gathered}
\operatorname{lam}=f(\%) \text { en bleu, } R c=f(\%) \text { en orang, } R f=f(\%) \text { en } \\
\text { maron }
\end{gathered}
$$

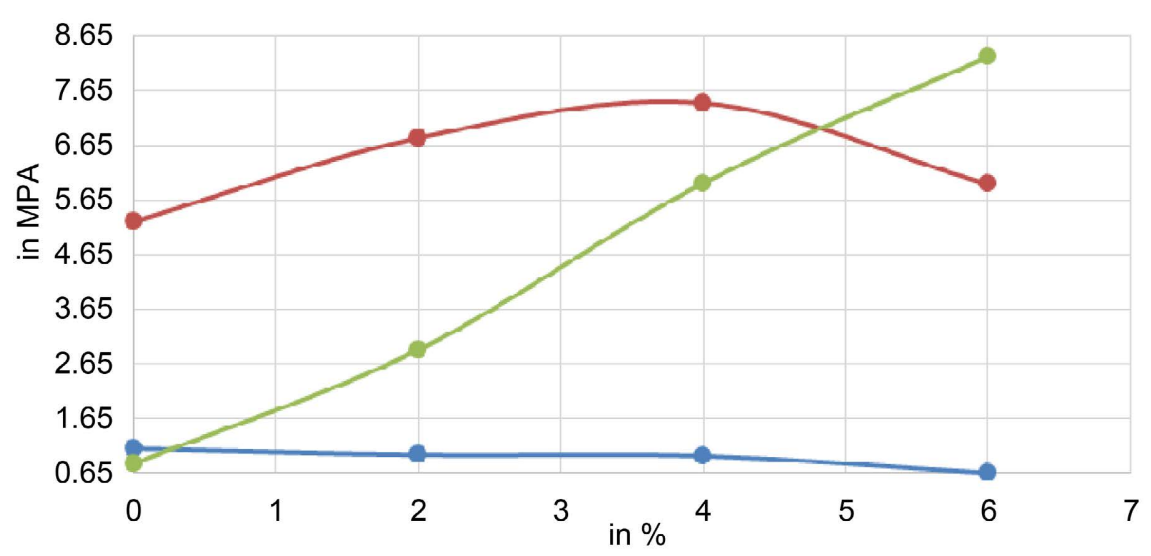

Figure 21. Evolution of thermal conductivity (blue), compressive strength (orange) and bending strength (brown) as a function of bamboo fiber content.

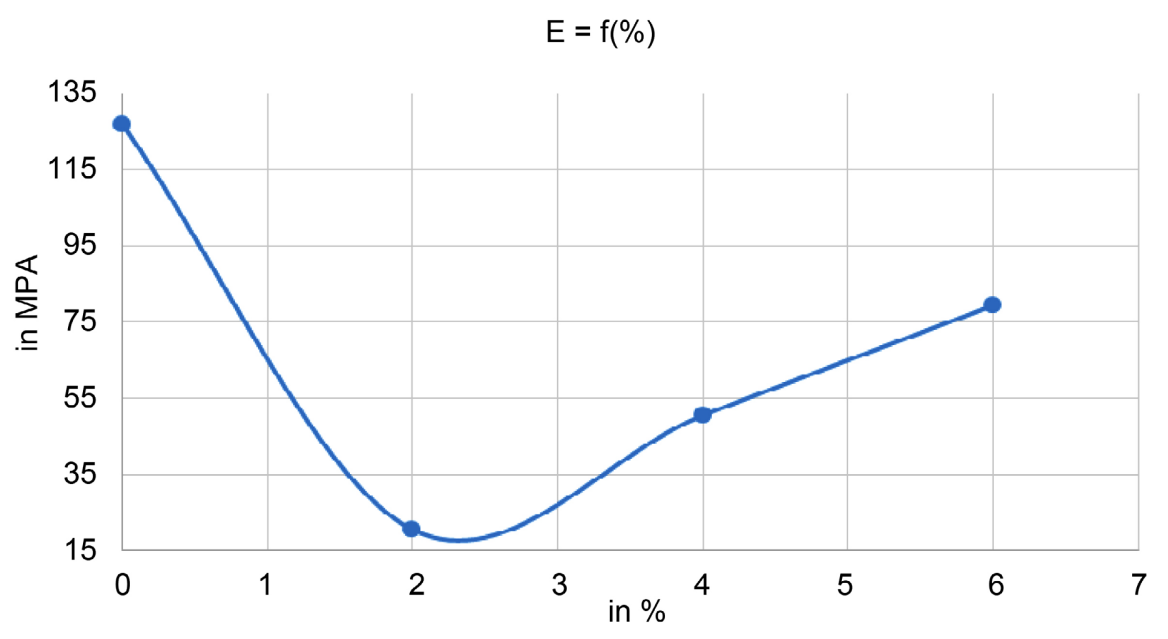

Figure 22. Evolution of the modulus of elasticity as a function of the bamboo fibre content.

subjected to certain stresses. This can be seen from the modulus of elasticity curve (Figure 21 and Figure 22) where it can be seen that for the $0 \%$ material, the modulus of elasticity is very high. This is in line with the low plasticity of the material observed during the granulometric study. The modulus of elasticity then decreases slightly following the addition of fibers $(2 \%, 4 \%)$ and begins to increase rapidly again beyond a content of $6 \%$, reflecting the fact that the good soil-fiber compromise is situated at a maximum rate of $6 \%$.

\section{Conclusions}

The objective of this research was to characterize the thermophysical and mechanical properties of an eco-material: poto-poto, made from earth with the addition of bamboo fiber at different levels.

An asymmetrical hot plane device was used to estimate the thermal conduc- 
tivity of these materials in order to verify their thermal insulation capacity. A mechanical characterization was carried out in order to verify its conformity with the requirements in Cameroon (MIPROMALO).

The results obtained showed that the addition of fibers to the material up to a maximum content of $6 \%$ can not only improve the thermal insulation performance of these materials and therefore contribute to energy savings in the building when used as filling materials, but also that they comply with the requirements of MIPROMALO, as they have a compressive strength above $2 \mathrm{MPa}$

Finally, the Young's modulus study justified that the addition of fibers above $6 \%$ would cause early failure of the material if used as a filler.

Since it is known that compressed lateritic earth composites provide good thermal inertia, we plan to study the thermal inertia of these materials (poto-poto) in a future study in order to verify whether they can also provide good thermal regulation at night. In this way, they could be recommended for use in cold climate regions.

\section{Conflicts of Interest}

The authors declare no conflicts of interest regarding the publication of this paper.

\section{References}

[1] MINTP (2009) Séminaire de renforcement des capacités des contrôleurs du Ministère des Travaux Publiques aux techniques de contrôle de qualité des constructions en BTC. Decembre.

[2] Constantinos, A., Athina, G., Elena, G., Sevastianos, M. and Yianni, S. (2007) European Residential Buildings and Empirical Assessment of the Hellenic Building Stock, Energy Consumption, Emissions and Potential Energy Savings. Building and Environment, 42, 1298-1314. https://doi.org/10.1016/j.buildenv.2005.11.001

[3] AFNOR (2012) Ciments et chaux. Partie 2.2: Chaux de construction.NF EN 459-2. AFNOR, Paris.

[4] Pettang, C., Vermande, P. and Zimmermann, M. (1995) L'impact du secteur informel dans la production de l'habitat urbain au Cameroun. Cahiers des Sciences Humaines, 31, 883-903.

[5] Chrispin, P. and Amos, F. (2000) Le béton de modules latéritiques armé de fibres végétales: Une alternative pour l'habitat économique dans le tiers monde. Bulletin Africain Bio ressources Energie. Développement. Environnement, 12, 12-19.

[6] Houben, H. (2009) Blocs de Terre Comprimé: Normes. CDI.

[7] Mekhermeche, A. (2012) Contribution à l'étude des propriétés mécaniques et thermiques des briques en terre en vue de leur utilisation dans la restauration des KsoursSahériens. Mémoire de magister, Université de Kasdi Merbah Ouargla, Ouargla.

[8] Bessennouci, M. (2010) Impact et contribution thermo énergétique de matériaux de construction à base pouzzolanique dans l'habitat. Mémoire de magister, University of Abou Bekr Belkaïd, Tlemcen.

[9] Nguyen, T.T (2010) Contribution à l'étude de la formulation et du procédé de fabrication d'éléments de construction en béton de chanvre, Thèse de doctorat $\mathrm{N}^{\circ} 170$, Université de Bretagne Sud, Lorient.

[10] Samri, D. (2008) Analyse physique et caractérisation hygrothermique des matériaux 
de construction: Approche expérimentale et modélisation numérique. Thèse de doctorat No 2008-ISAL-0067.

[11] Mbessa, M., Ndongo, E.C., et al. (2011) Influence of the Powder of Pouzzolana on Some Properties of the Concrete: Case of Pouzzolane of Djoungolo (Cameroon). International Journal of Modem Engineering Research, 2, 4162-4165.

[12] Asangwing, V. (2010) Optimisation of Formulations of Stabilised Earth Blocks Using Local Natural Fibers for Home Construction. ENSET, Douala.

[13] Meukam, P. (2004) Caractérisation de matériaux locaux en vue de l'isolation thermique de bâtiments. Thèse de Doctorat PhD, ENSP, Université de Yaoundé I, Cameroun.

[14] Pepple, O., Ogbanda, C. and Opara, F. (2010) Thermal Conductivity of Reinforced Cement Stabilized Lateritic Brick. Journal of Engineering and Applied Sciences, 5, 178-180. https://doi.org/10.3923/jeasci.2010.178.180

[15] Bilong, N., Louvet, F., Njopwouo, D. and ChinjeMelo, U.F. (2009) Properties of Compressed Lateritic Soil Stabilized with a Burnt Clay-Lime Binder: Effect of Mixture Components. Construction and Building Materials, 23, 2457-2460. https://doi.org/10.1016/j.conbuildmat.2008.09.017

[16] Zannou, O. (2003) Etude comparées des propriétés mécaniques et thermophysiques des briques en terre stabilisée au ciment et en argile cuite. Mémoire du Diplôme d’Ingénieur Agronome. Université D’Abomey-Calavi, Benin.

[17] Elimbi, A. et al. (2005) Protocoles d'analyses des matières premières et des produits finis au laboratoire. MIPROMALO.

[18] Boubekeur, S. and Houben, R. (1998) (CRATerre-EAG), Blocs de terre comprimée. Normes. CDI et CRATerre-EAG.

[19] Maillet, D., Andre, S., Batsale, J.C., Degiovanni, A. and Moyne, C. (2000) Thermal Quadrupoles. John Wiley \& Sons, New York.

[20] Jannot, Y., Remy, B. and Degiovanni, A. (2010) Measurement of Thermal Conductivity and Thermal Resistance with Tiny Hot Plate. High Temperatures-High Pressure, 39, 11-31.

[21] Batsale, J.C., Maillet, D. and Degiovanni, A. (1994) Extension de la méthode des quadripôles thermique à l'aide des transformations intégrales, calcul du transfert thermique au travers d'un défaut plan bidimensionnel. International Journal of Heat and Mass Transfer, 37, 111-127. https://doi.org/10.1016/0017-9310(94)90166-X

[22] Jannot, Y. (2011) Cours de Métrologie Thermique, LEMTA-CNRS.

[23] Damfeu, J.C., Meukam, P., Jannot, Y. and Wati, E. (2017) Modelling and Experimental Determination of Thermal Properties of Local Wet Building Materials. Energy and Buildings, 135, 109-118. https://doi.org/10.1016/j.enbuild.2016.11.022

[24] Levenberg, K. (1944) A Method for a Solution of Certain Non-Linear Problems in Least-Squares. Quarterly of Applied Mathematics, 2, 164-168. https://doi.org/10.1090/qam/10666

[25] De Hoog, F.R. (1982) An Improved Method for Numerical Inversion of Laplace Transforms. SIAM Journal on Scientific and Statistical Computing, 3, 357-366. https://doi.org/10.1137/0903022

[26] Meukam, P., Noumowe, A., Jannot, Y. and Duval, R. (2003) Thermophysical and Mechanical Characterization of Stabilized Clay Blocks for Building Thermal Isolation. Materials and Structures, 36, 453-460. https://doi.org/10.1007/BF02481525 